\title{
NOTE ON MULTIPLE REVIEWS
}

\author{
Tyrone A. Forman, Book Review Editor \\ Department of Sociology, Emory University
}

As readers of the Du Bois Review: Social Science Research on Race are well aware, this journal aims to be the principal journal for social scientists exploring the intersection of race, ethnicity and culture. As book review editor it gives me great pleasure to introduce a new feature of the journal to our readers. From time to time in the State of the Discourse section of the Du Bois Review we will spotlight multiple reviews of a single book. In focusing intently on a single contribution our purpose is to highlight significant pieces of scholarship that provide novel conceptual and/or empirical analysis of ethnoracial dynamics in society. We are especially interested in bringing to the attention of our readers books that provide alternative frameworks and/or set new and daring intellectual agendas for the study of race and ethnicity.

In this issue of the Du Bois Review, two prominent social scientists, social demographer Reynolds Farley and sociological social psychologist Lawrence Bobo, assess the contribution of Categorically Unequal: The American Stratification System by Princeton sociologist Douglas Massey. This important work examines the principal ways that structured social inequality is sustained in contemporary U.S. society. It gives close attention to the trifecta of modern inequality: race, class, and gender. Whether or not one agrees with Massey's assessment of what the late Charles Tilly labeled "durable inequality," his core arguments about the complexity of the human condition and human experiences are thought provoking and worthy of further social scientific interrogation.

Want to suggest a book for consideration? Send your book nomination ideas to tforman@emory.edu with “DBR book nomination” in the subject line. 